OPEN ACCESS

Edited by:

Brahim Aissa,

MPB Technologies \&

Communications, Canada

Reviewed by:

Adnan Ali,

Qatar Foundation, Qatar Mahyar Mohammadnezhad, Université du Québec, Canada

*Correspondence: Long Chen 812612937@qq.com

Specialty section: This article was submitted to Smart Materials,

a section of the journal

Frontiers in Materials

Received: 21 April 2020

Accepted: 24 July 2020

Published: 18 August 2020

Citation:

Chen L, Zhang Y, Liu W and Liu Z (2020) Graphene Nanoarchitectonics: A New Material Horizon for Reinforcement of Sustainable Polymers. Front. Mater. 7:276. doi: $10.3389 /$ fmats.2020.00276

\section{Graphene Nanoarchitectonics: A New Material Horizon for Reinforcement of Sustainable Polymers}

\author{
Long Chen*, Yishu Zhang, Wenping Liu and Zhanqiang Liu \\ Key Laboratory of High Efficiency and Clean Mechanical Manufacture of MOE, Shandong University, Jinan, China
}

Using nanoscience to solve the issues that limit the development of a sustainable society is one of the most important topics at present. Sustainable polymers play an important role in the construction of a sustainable society, but its large-scale application is usually limited by the poor mechanical and shape-memory properties of the commonly used epoxy resin. The utilization of nanoarchitectures to improve the shape-memory performance of composite materials is an effective approach. Graphene, among the used reinforcement materials for epoxy resin, is undoubtedly a fascinating example. In this paper, the shape-memory and mechanical properties of graphene-modified epoxy resins are described respectively for different response types. In this minireview, we present an overview of the research results of graphene nanoarchitectonics in the modification of shape-memory epoxy resin composites. Besides, this paper has reviewed the properties of different types of graphene/epoxy composites, looking forward to the development of graphene/epoxy composites and future prospects.

Keywords: graphene, nanoarchitectonics, composites, sustainability, polymers

\section{INTRODUCTION}

A sustainable polymer is a kind of material that can change shape and recover under certain conditions, such as heat, light, water, $\mathrm{pH}$, and other external stimuli (Zhao et al., 2015; Yao et al., 2018). Shape-memory characteristics have broad application prospects in aerospace, biomedical, and other fields (Fabrizio et al., 2012; Li et al., 2012; Zhao et al., 2019). Among the sustainable polymer series materials, epoxy (EP) resin has attracted considerable attention both scholarly and popularly due to their excellent shape-memory properties, thermal properties, and mechanical properties (Liu et al., 2010).

Related researches pointed out that the interaction between nanoparticles and polymer matrix can accelerate the movement of molecular chains, improving the shape-memory performance of materials (Babaahmadi et al., 2017). Graphene has been considered as an irreplaceable reinforcing material because of its special structure and excellent properties and has great application value 
in the field of composite modification. Wang et al. (2018) introduced graphene into EP-cyanate ester nanocomposites, and the results confirmed that graphene could promote the shape recovery of EP cyanate nanocomposites. It should be noted that the doped size, surface modification, and dispersion of graphene as a filler will have a significant impact on the performance of composite materials (Atif et al., 2016). For instance, functionalized graphene (FG) can obtain good bonding with the matrix, thereby enhancing the role of graphene as reinforcing filler (Choi et al., 2012). A novel slippery film with tunable wettability based on a shape-memory graphene sponge was presented by Wang et al. (2017). The shape-memory polymer was coated on the surface of porous graphene sponge, which was used to lock in inert lubricant and to construct a smooth surface to achieve good hydrophobicity. The superelasticity, high strength, and good conductivity of graphene sponge endow graphene/polymer hybrid films with good shape-memory properties. In fact, in addition to graphene, its derivatives, such as graphene oxide (GO) and thermally reduced graphene, are often used as fillers to modify composite materials (Kausar, 2019). At present, the use of graphene to modify shape-memory EP resins to prepare shape-memory graphene/EP resin composites with better shape-memory and mechanical properties has been widely investigated by scholars. Table 1 shows the literature summary of graphene-modified shape-memory EP resin. It can be seen from the table that different doping processes and dosage can improve the mechanical properties of shape-memory EP resin to a different extent. For different types of shape-memory EP resin, different graphene content can change its recovery performance correspondingly.

In this article, we summarized the recent developments of graphene nanoarchitectonics in a reinforcement of shapememory polymers under various external stimuli like thermal, electrical, and other stimulations and discussed the problems of graphene in limiting the application of composites (Figure 1).

\section{THERMO-ACTIVE GRAPHENE/EPOXY COMPOSITES}

Thermo-induced shape-memory materials are the most widely studied type of shape-memory polymers. The shape-memory EP can be divided into the stationary phase and reversible phase, in which the stationary phase is used for shape-memory and recovery. When the temperature rises above the glass transition temperature $\left(\mathrm{T}_{\mathrm{g}}\right)$, the material can deform under the effect of external load, and the reversible phase molecular chain is frozen when cooled, to obtain a stable morphology. When the temperature rises above $\mathrm{T}_{\mathrm{g}}$ again, the reversible phase molecular chain recovers its activity and releases the stored strain energy, and the material returns to its original state gradually under the recovery of the stationary phase (Wang et al., 2019b; Willian and Cristina, 2020).

Recently, studies have shown that carbon nanomaterials can improve the thermally activated shape-memory properties of materials (Park et al., 2014; Liu et al., 2016). Ortiz et al. (2018) prepared a photocurable shape-memory EP/thiol-ene/graphene

nanoplatelete (GNP) composites that can be cured by light. By increasing the concentration of GNP and polythioethers in the co-network, the thermal conductivity increases almost linearly. According to the experimental data, the thermal conductivity of the sample with a concentration of polythioether $(40 \% \mathrm{~mol})$ and graphene (15 wt\%) reaches the maximum, which is $0.39 \mathrm{~W} / \mathrm{m} \mathrm{K}$. They also studied the shape-memory properties of the material, and the results showed that samples with $10 \%$ of GNP at all thiol-ene concentrations presented the best results in both shape recovery and shape fixity value, which was in the range of 95-99\%. Meanwhile, the experimental results also found that the presence of soft domains (such as polythioethers) in the cross-linked co-network helps to enhance the shape-memory characteristics of GNP nanocomposites. GO/waterborne EP shape-memory composites were prepared by Wang et al. (2019a). In the experiments, they found that as the content of GO increases, the storage modulus of the material increases. The

TABLE 1 | Overview of shape-memory and mechanical properties of widely used graphene.

\begin{tabular}{llll}
\hline $\begin{array}{l}\text { Doping } \\
\text { methods }\end{array}$ & $\begin{array}{l}\text { Graphene } \\
\text { content }\end{array}$ & Performance & References \\
\hline $\begin{array}{l}\text { Ultrasonic } \\
\text { dispersion }\end{array}$ & $5-15$ wt\% & $\begin{array}{l}\text { Tensile strength and } \\
\text { elongation were increased by } \\
\text { 5.3 and 33.5\%, respectively }\end{array}$ & $\begin{array}{l}\text { Zhang L. et al., } \\
2016 ; \text {; Ortiz et al., } \\
\end{array}$ \\
& & & $2019 \mathrm{~b}$ ang et al.,
\end{tabular}

Vacuum- $\quad 2-12$ wt\% Enhance the structure of the Fejos et al., 2013; assisted resin nanofiber web (increased Wang et al., 2015; transfer 15\%)

Solution $\quad 1-3 w t \% \quad$ Young's modulus and tensile Zhou et al., 2016 casting strength of nanocomposites Nouri et al., 2020 prepared via R(GO-ISO) nanosheets have been improved (increased $51 \mathrm{MPa}$ )

Solution blending $0.1-4 w t \%$

Moduli of the imidized graphene nanocomposites were 25-30\% higher than those of unmodified graphene nanocomposites. The addition of graphene improved the recovery rate

\begin{tabular}{|c|c|c|c|}
\hline $\begin{array}{l}\text { Compound } \\
\text { aerogels }\end{array}$ & $\begin{array}{l}0.5-0.8 \\
w t \%\end{array}$ & $\begin{array}{l}\text { Compared with pure epoxy, } \\
\text { the electrical conductivity of } \\
\text { the composite is improved by } \\
13 \text { orders of magnitude }\end{array}$ & Liu et al., 2015 \\
\hline $\begin{array}{l}\text { Coupling } \\
\text { reaction }\end{array}$ & $2-6 w t \%$ & $\begin{array}{l}\text { A modulus of } \sim 339 \mathrm{MPa} \text { and } \\
\text { a shape recovery ratio of } \\
98 \% \text { were achieved }\end{array}$ & $\begin{array}{l}\text { Zhang and } \mathrm{Hu} \\
(2020)\end{array}$ \\
\hline $\begin{array}{l}\text { In situ } \\
\text { polymerization }\end{array}$ & $\begin{array}{l}0.5-1.5 \\
w t \%\end{array}$ & $\begin{array}{l}\text { Young's modulus of PU/GQD } \\
\text { nanocomposites increases } \\
\text { with the addition of GQDs } \\
\text { content at both room } \\
\text { temperature and } 60^{\circ} \mathrm{C}\end{array}$ & $\begin{array}{l}\text { Sanaz et al., 2020; } \\
\text { Sarabiyan et al., } \\
2020\end{array}$ \\
\hline $\begin{array}{l}\text { Condensation } \\
\text { polymerization }\end{array}$ & $\begin{array}{l}0.1-1.0 \\
w t \%\end{array}$ & $\begin{array}{l}\text { The nanocomposite film } \\
\text { containing } 0.25 w t \% \text { GNPs } \\
\text { showed the highest shape } \\
\text { recovery ratio ( } 92.4 \%) \text { since } \\
\text { the net-point effect }\end{array}$ & $\begin{array}{l}\text { Maryam et al., } \\
2020\end{array}$ \\
\hline
\end{tabular}

GQD, graphene quantum dot; PU, polyurethane; GNP, graphene nanoplatelete. 


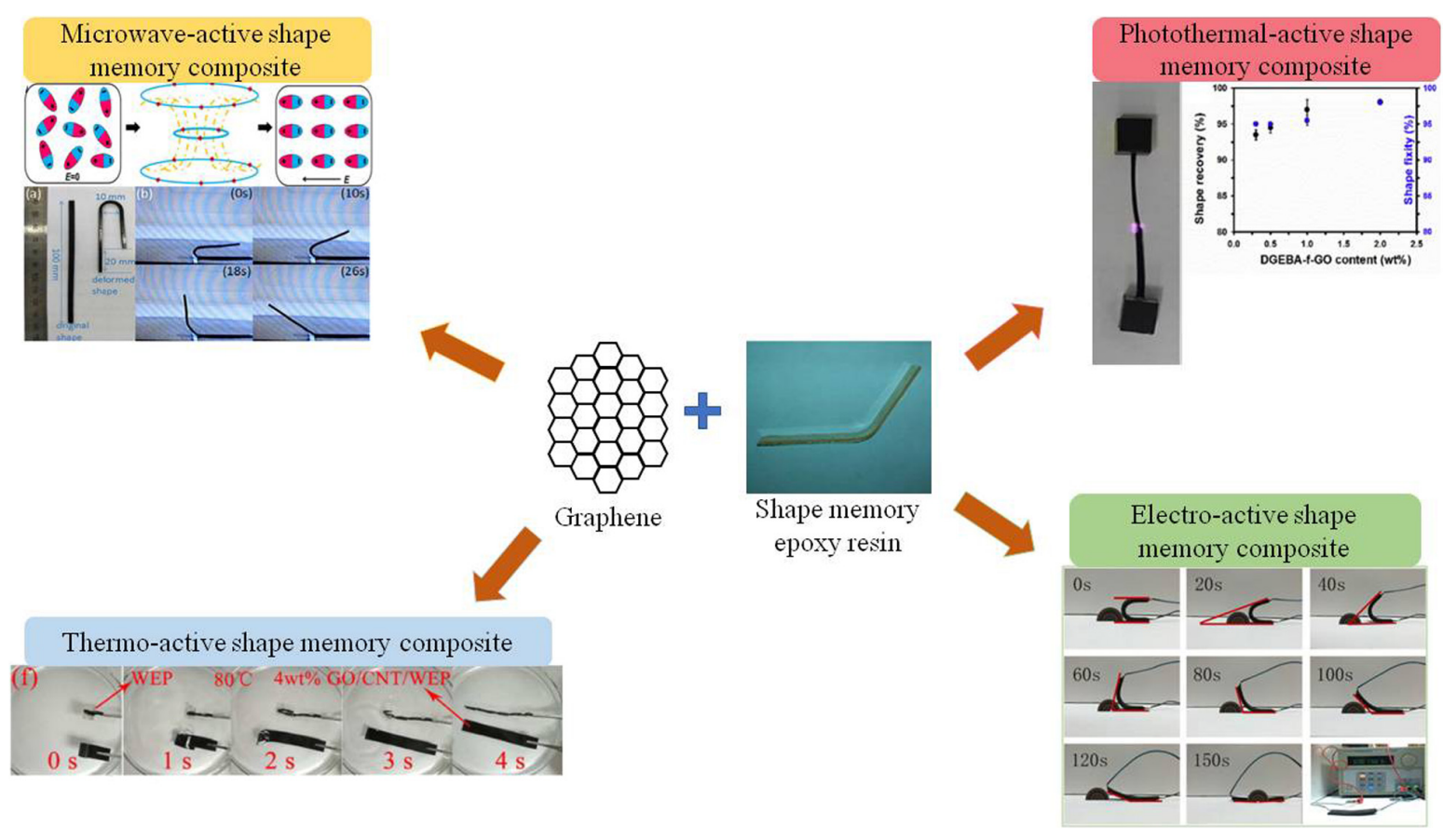

FIGURE 1 | Shape-memory graphene/epoxy composites with different driving modes. Reproduced from Zhang et al. (2015) with permission from Nature Publishing Group. Reproduced from Chen et al. (2018) with permission of Wiley. Reproduced from Yi et al. (2014) with permission of Academic Press Inc. Elsevier Science. Reproduced from Punetha et al. (2019) with permission of Elsevier. Reproduced from Zhou et al. (2016) with permission of Elsevier. Reproduced from Wang et al. (2019a) with permission of Elsevier. Reproduced from Liu et al. (2010) with permission of Elsevier.

study showed that the addition of GO would improve the shape recovery rate and fixation rate of shape-memory EP materials and would increase the thermal response speed. Also, compared with pure WEP, the mechanical properties of the material have also improved. Subsequently, they also prepared GO/carbon nanotube (CNT)/WEP ternary hybrid polymeric shape-memory composites. The results show that GO and CNT show excellent synergistic enhancement effects in many aspects.

To solve the brittleness of the EP resin matrix, Zhang L. et al. (2016) used polyurethane (PU)/EP interpenetrating polymer network material as the matrix and introduced FG to prepare PU/FG/EP composites. The experimental results show that the FG has a strong binding force with the matrix. When $0.8 \mathrm{wt} \%$ FG was added, the tensile strength and elongation at break of the material were increased by 5.3 and $33.5 \%$, respectively, and with the increase of FG load, the shape-memory property was enhanced continuously. When the FG content is $1.0 \mathrm{wt} \%$, the values of shape fixity and shape recovery reach maximum, which are 96 and $94 \%$, respectively. With the increasing of FG load, the shape-memory performance of the material decreased. This may be due to the agglomeration of high-content graphene and the interference of the increasing of graphene content on the fluidity of polymer in slender nanofibers. Other researchers have found similar phenomena (Das et al., 2016; Jiu et al., 2016; Chen et al., 2019). Graphene agglomeration is the result of van der Waals forces. Many processes have been proven to help avoid filler agglomeration and improve the dispersion of graphene (Atif and Inam, 2016).
In addition to the dual shape-memory effect, the triple-shapememory composite materials have also attracted great interest from researchers. Triple-shape-memory polymers refer to shapememory polymers capable of memorizing two temporary shapes in one shape-memory cycle (Zhang Q. et al., 2016; Fatemeh et al., 2017; Du et al., 2019). Fejos et al. (2013) used graphene nanosheets to reinforce polycaprolactone (PCL) nanofiber webs and then infiltrated EP into nanofiber webs by vacuum-assisted resin transfer molding to prepare triple-shape-memory EP/PCL system. The experimental results show that graphene filling can effectively enhance the structure of the nanofiber web, but it will also destroy the shape-memory properties of the PCL phase.

\section{ELECTRO-ACTIVE GRAPHENE/EPOXY COMPOSITES}

Thermal-active shape-memory polymer materials are limited by the direct heating temperature when excited, whereas electroactive shape-memory polymer is motivated by applying voltage, so it is more convenient to use than thermal-active shapememory polymer materials ( $\mathrm{Lu}$ and Gou, 2012; Meng and Li, 2013). Electromechanical shape-memory polymers use Joule heat generated by electrical current to trigger the shapememory effect. However, due to the insulating properties of most polymers, researchers have introduced graphene into shape-memory material systems and improved the electrical conductivity of materials by building conductive paths to 
improve the electro-active shape-memory effect (Li et al., 2016; Sabzi et al., 2016; Sofla et al., 2019).

Zhou et al. (2016) prepared three-dimensional PU-based graphene foam/EP/CNT (PGEC) shape-memory composites using shape-memory EP as a matrix, $\mathrm{PU}$ sponges as the stent, and graphene and CNTs as a conductive network. The conductivity of materials with different graphene contents is not the same. As the graphene content increases, a threedimensional graphene network structure is gradually formed, and the electrical conductivity of the material is sharply increased. When the graphene content is $12 \mathrm{wt} \%$, the average conductivity of the material reaches $3.33 \mathrm{~S} / \mathrm{m}$. A shape recovery test was performed on a PGEC composite containing $8 \%$ graphene and $3 \%$ CNTs. It was found that the shape fixation rate of the material was $98 \%$. At $100 \mathrm{~V}$, the sample almost restored its original shape in $150 \mathrm{~s}$, with the shape recovery rate reaching $96 \%$. Wang et al. (2015) prepared a reduced GO paper/EP-based shape-memory composite by using a resin transfer molding method to coat shape-memory-reduced GO paper on the surface of a shapememory EP resin. Bending experiments tested the shape-memory performance of the material, and the surface temperature was detected with an infrared imager. The experimental results showed that when the voltage of $6 \mathrm{~V}$ is applied, the material is heated uniformly and can reach $98 \%$ shape recovery rate within $5 \mathrm{~s}$. CNTs and graphene compound aerogels were prepared first, and then, nano-aerogel/shape-memory EP composites were obtained by impregnation with monomer EP resin by Liu et al. (2015). Compared with pure EP, the electrical conductivity of the composite is improved by 13 orders of magnitude, reaching a maximum of $5.2 \mathrm{~S} / \mathrm{m}$. In the shape-memory performance test, there was a shape recovery process of the compound aerogel (the weight ratio of CNTs to graphene is 3:5)/EP resin composite at $60 \mathrm{~V}$. In the first $20 \mathrm{~s}$, the recovery rate was only 0.5 degrees per second; subsequently, it gradually increased to 2.1 degrees per second. Finally, in the last $30 \mathrm{~s}$, the recovery rate decreased to about 0 degrees, due to most of the stress released at an early stage.

\section{OTHER TYPES OF GRAPHENE/EPOXY COMPOSITES}

Shape-memory materials that can be remotely and wirelessly driven have broad application prospects in space engineering, which has attracted widespread attention. Microwave-active shape-memory material is one of them. Microwaves can trigger this kind of shape-memory materials because the dipoles in the materials are oriented and polarized under the action of microwaves. During the deformation process, there will be friction loss and heat generation during the excitation of the microwave-responsive shape-memory material (Zhang et al., 2015; Du et al., 2016). However, the microwave absorption capacity of general shape-memory materials is very low, so it is necessary to introduce enhanced absorbing fillers to improve the orientation polarization performance (Yu et al., 2014; Du et al., 2015; Likitaporn et al., 2018).
Chen et al. (2018) prepared shape-memory nanocomposites using EP-based shape-memory polymer (ESMP) as the matrix. This shape-memory nanomaterial is filled with zero-dimensional carbon black, one-dimensional multiwalled CNTs (MWCNT$\mathrm{COOH}$ ), two-dimensional graphene nanosheets (GNPs), and three-dimensional functional graphene sheets (FGSs). The nanofiller content was $2.15 \mathrm{wt} \%$ in all nanocomposites. The results of microwave heating experiments showed that GNP/ESMP nanocomposites heat the fastest under the same microwave power. In the shape-memory test, the shape fixation rate of the four nanocomposites was above $97 \%$ under 60 W microwave radiation. Except for MWCNT-COOH/ESMP nanometers, the shape recovery rate of other composite materials can reach $100 \%$ in 10-min microwave heating, and the FGS/ESMP nanocomposite material requires the shortest time, only $250 \pm 15 \mathrm{~s}$. This is because FGS/ESMP nanocomposites have the fastest heating speed.

In addition to microwave-active shape-memory materials, photo/thermal-active shape-memory material is also one of the materials that facilitate remote driving (Herath et al., 2019; Huang et al., 2019; Li et al., 2019; Kang et al., 2019). Photo/thermal actuators are made by doping fillers in a photo/thermal-active shape-memory polymer matrix ( $\mathrm{Lu}$ et al., 2014; Yi et al., 2014). Punetha et al. (2019) prepared bisphenol A diglycidyl ether-functionalized GO (DGEBA-f-GO)based PU/EP nanocomposites, and the photo/thermal behavior and shape-memory of the performance of the material were investigated. The research results show that with the increase of the content of DGEBA-f-GO, the shape recovery performance of the material under the driving of infrared laser is continuously improved. The shape recovery rate of $2.0 \mathrm{wt} \%$ DGEBA-f-GO reaches $98 \%$, and the DGEBA-f-GO nanocomposites still exhibit good shape-memory performance after repeated cycles.

\section{CONCLUSION}

In summary, recent researches on graphene/EP composites have brought up a great deal of government and social attention and support. The research results showed that graphene/EP composite material is an intelligent material with important application potential. In addition to its excellent shape-memory function, it also has the characteristics of high strength, wide adjustable range of stiffness, and easy processing and forming. However, the current research on shape-memory graphene/EP composites also has many problems that need to be solved:

- The content of graphene has a great influence on the shape-memory performance of the material. Improper content of graphene can agglomerate in the shape-memory materials, and the aggregation of graphene significantly reduces the strengthening effect of graphene. Therefore, improving the dispersibility of graphene in $\mathrm{EP}$ resin and the interface compatibility of shape-memory composites is still a technical problem that needs to be urgently solved.

- To accurately realize the specific deformation of the shape-memory polymer structure in practical applications, 
according to the special properties of the shape-memory composite material, the thickness dimension of the shapememory graphene/EP resin should be limited. In the design of the shape-memory material structure, to prevent the fiber-reinforced material from falling off the resin matrix due to the irrational dimensional structure when the structure is deformed, it is necessary to limit the parameters such as outer size, thickness, and bending radius. Therefore, the application range of shape-memory composites will inevitably be affected.

- At present, the researches on shape-memory graphene/EP resin only focus on the static properties of the material. The dynamic changes of parameters such as glass transition temperature, elastic modulus, and thermal expansion coefficient caused by the preparation method and the graphene doping process are ignored. Also, the temperature change rate and temperature decrease rate in the preparation process may also have a certain effect on the memory performance of the material. Therefore, studying the properties of composite materials under dynamic conditions is also a problem that researchers need to solve.

\section{REFERENCES}

Atif, R., and Inam, F. (2016). Reasons and remedies for the agglomeration of multilayered graphene and carbon nanotubes in polymers. Beilstein J. Nanotech. 7, 1174-1196. doi: 10.3762/bjnano.7.109

Atif, R., Shyha, I., and Inam, F. (2016). Mechanical, thermal, and electrical properties of graphene-epoxy nanocomposites -a review. Polymers 8:281. doi: $10.3390 /$ polym 8080281

Babaahmadi, M., Sabzi, M., Mandavinia, G. R., and Keramati, M. (2017). Preparation of amorphous nanocomposites with quick heat triggered shape memory behavior. Polymer 112, 26-34. doi: 10.1016/j.polymer.2017.01.074

Chen, G., Wu, K., Zhang, Q., Shi, Y., and Lu, M. (2019). Dual-responsive shape memory and thermally reconfigurable reduced graphene oxide-vitrimer composites. Macromol. Res. 27, 526-533. doi: 10.1007/s13233-019-7080-x

Chen, L., Liu, Y., and Leng, J. (2018). Microwave responsive epoxy nanocomposites reinforced by carbon nanomaterials of different dimensions. J. Appl. Polym. Sci. 135:45676. doi: 10.1002/app.45676

Choi, J. T., Dao, T. D., Oh, K. M., Lee, H. I., Jeong, H. M., and Kim, B. K. (2012). Shape memory polyurethane nanocomposites with functionalized graphene. Smart Mater. Struct. 21:075017. doi: 10.1088/0964-1726/21/7/075017

Das, R., Banerjee, S. L., and Kundu, P. P. (2016). Fabrication and characterization of in situ graphene oxide reinforced high-performance shape memory polymeric nanocomposites from vegetable oil. RSC Adv. 6, 27648-27658. doi: 10.1039/ c5ra25744a

Du, H., Liu, L., Zhang, F., Leng, J., and Liu, Y. (2019). Triple-shape memory effect in a styrene-based shape memory polymer: characterization, theory and application. Compos. Part B-Eng. 173:106905. doi: 10.1016/j.compositesb.2019. 106905

Du, H., Liu, X., Yu, Y., Xu, Y., Wang, Y., and Liang, Z. (2016). Microwave-induced poly(ionic liquid)/poly(vinyl alcohol) shape memory composites. Macromol. Chem. Phys. 217, 2626-2634. doi: 10.1002/macp.201600379

Du, H., Song, Z., Wang, J., Liang, Z., Shen, Y., and You, F. (2015). Microwaveinduced shape-memory effect of silicon carbide/poly(vinyl alcohol) composite. Sensor. Actuat. A-Phys. 228, 1-8. doi: 10.1016/j.sna.2015.01.012

Fabrizio, Q., Loredana, S., and Anna, S. E. (2012). Shape memory epoxy foams for space applications. Mater. Lett. 69, 20-23. doi: 10.1016/j.matlet.2011.11.050

Fatemeh, K., Ismaeil, G., Massimo, M., et al. (2017). Nanocomposites based on poly(L-lactide)/poly( $\varepsilon$-caprolactone) blends with triple-shape memory behavior: effect of the incorporation of graphene nanoplatelets (GNps). Compos. Sci. Technol. 151, 219-227. doi: 10.1016/j.compscitech.2017.08.021
Shape-memory graphene/EP composites still have a broad development space. If the previously discussed problems can be effectively solved, the application of shape-memory graphene/EP composites will be more extensive in the future.

\section{AUTHOR CONTRIBUTIONS}

LC and YZ produced and wrote the manuscript. LC and WL edited the manuscript. LC and ZL edited the manuscript and supervised. All authors read and approved the manuscript.

\section{FUNDING}

This work was supported by the 13th Five-Year Plan Equipment Pre-Research Fund under Grant No. 61402060404, the Natural Foundation of Shandong Province under Grant No. ZR2019BEE068, the State Key Laboratory of Mechanical System and Vibration under Grant No. MSV-2019-13, and the Fundamental Research Funds of Shandong University under Grant No. 2018GN034.

Fejos, M., Molnar, K., and Karger-Kocsis, J. (2013). Epoxy/polycaprolactone systems with triple-shape memory effect: electrospun nanoweb with and without graphene versus co-continuous morphology. Materials 6, 4489-4504. doi: 10.3390/ma6104489

Herath, M., Epaarachchi, J., Islam, M., Yan, C., Zhang, F., and Leng, J. (2019). Effects of selectively triggered photothermal particles on shape memory polymer composites: an investigation on structural performance, thermomechanical characteristics and photothermal behavior. J. Intel. Mat. Syst. Str. 30, 3124-3135. doi: 10.1177/1045389X19879998

Huang, C., Peng, J., Cheng, Y., and Zhao, Q. (2019). Ultratough nacre-inspired epoxy-graphene composites with shape memory properties. J. Mat. Chem. A 7, 2787-2794. doi: 10.1039/C8TA10725D

Jiu, H., Jiao, H., Zhang, L., Zhang, S., and Zhao, Y. (2016). Graphenecrosslinked two-way reversible shape memory polyurethane nanocomposites with enhanced mechanical and electrical properties. J. Mater. Sci.-Mater. El. 27, 10720-10728. doi: 10.1007/s10854-016-5173-2

Kang, S., Kang, T., Kim, B., et al. (2019). 2D reentrant micro-honeycomb structure of graphene-CNT in polyurethane: high stretchability, superior electrical/thermal conductivity, and improved shape memory properties Compo. Part B Eng. 162, 580-588. doi: 10.1016/j.compositesb.2019.01.004

Kausar, A. (2019). Shape memory polyurethane/graphene nanocomposites: structures, properties, and applications. J. Plast. Film Sheet 36:875608791986529. doi: 10.1177/8756087919865296

Li, C., Adamcik, J., and Mezzenga, R. (2012). Biodegradable nanocomposites of amyloid fibrils and graphene with shape-memory and enzyme-sensing properties. Nat. Nanotechnol. 7, 421-427. doi: 10.1038/nnano.2012.62

Li, C., Qiu, L., Zhang, B., Li, D., and Liu, C. (2016). Robust vacuum-/air-dried graphene aerogels and fast recoverable shape-memory hybrid foams. $A d v$. Mater. 28, 1510-1516. doi: 10.1002/adma.201504317

Li, S., Jin, X., Shao, Y., Qi, X., Yang, J., and Wang, Y. (2019). Gold nanoparticle/reduced graphene oxide hybrids for fast light-actuated shape memory polymers with enhanced photothermal conversion and mechanical stiffness. Eur. Polym. J. 116, 302-310. doi: 10.1016/j.eurpolymj.2019.04.029

Likitaporn, C., Mora, P., Tiptipakorn, S., and Rimdusit, S. (2018). Recovery stress enhancement in shape memory composites from silicon carbide whisker-filled benzoxazine-epoxy polymer alloy. J. Intel. Mat. Syst. Str. 29, 388-396. doi: 10.1177/1045389X17708041

Liu, X., Li, H., Zeng, Q., Zhang, Y., Kang, H., Duan, H., et al. (2015). Electro-active shape memory composites enhanced by flexible carbon nanotube/graphene aerogels. J. Mater. Chem. A 3, 11641-11649. doi: 10.1039/c5ta02490k 
Liu, Y., Han, C., Tan, H., and Du, X. (2010). Thermal, mechanical and shape memory properties of shape memory epoxy resin. Mat. Sci. Eng. A-Struct. 527, 2510-2514. doi: 10.1016/j.msea.2009.12.014

Liu, Y., Zhao, J., Zhao, L., Li, W., Zhang, H., Yu, X., et al. (2016). high performance shape memory epoxy/carbon nanotube nanocomposites. ACS Appl. Mater. Inter. 8, 311-320. doi: 10.1021/acsami.5b08766

Lu, H., and Gou, J. (2012). Fabrication and electroactive responsive behavior of shape-memory nanocomposite incorporated with self-assembled multiwalled carbon nanotube nanopaper. Polym. Advan. Technol. 23, 1529-1535. doi: 10. 1002/pat.2074

Lu, H., Yao, Y., Huang, W., Leng, J., and Hui, D. (2014). Significantly improving infrared light-induced shape recovery behavior of shape memory polymeric nanocomposite via a synergistic effect of carbon nanotube and boron nitride. Compos. Part B-Eng. 62, 256-261. doi: 10.1016/j.compositesb.2014. 03.007

Maryam, Z., Babak, K., Józef, T. H., and Lukasz, P. (2020). Shape memory thin films of Polyurethane: does graphene content affect the recovery behavior of Polyurethane nanocomposites? Polym. Compos. doi: 10.1002/pc.25627

Meng, H., and Li, G. (2013). A review of stimuli-responsive shape memory polymer composites. Polymer 54, 2199-2221. doi: 10.1016/j.polymer.2013.02.023

Nouri, N., Rezaei, M., Sofla, M. L. R., and Babaie, A. (2020). Synthesis of reduced octadecyl isocyanate-functionalized graphene oxide nanosheets and investigation of their effect on physical, mechanical, and shape memory properties of polyurethane nanocomposites. Comp. Sci. Tech. 194:108170. doi: 10.1016/j.compscitech.2020.108170

Ortiz, R. A., Valdez, A. E. G., Arguello, G. S., Padilla, G. M., and Berlanga, O. A. (2018). Photocurable shape-memory polyether-polythioether/graphene nanocomposites and the study of their thermal conductivity. J. Polym. Res. 25:160. doi: 10.1007/s10965-018-1552-0

Park, J., Dao, T., Lee, H., Jeong, H. M., and Kim, B. K. (2014). Properties of graphene/shape memory thermoplastic polyurethane composites actuating by various methods. Materials 7, 1520-1538. doi: 10.3390/ma7031520

Punetha, V. D., Ha, Y. M., Kim, Y. O., Jung, Y. C., and Cho, J. W. (2019). Interaction of photothermal graphene networks with polymer chains and laserdriven photo-actuation behavior of shape memory polyurethane/ epoxy/epoxyfunctionalized graphene oxide nanocomposites. Polymer 181:121791. doi: 10. 1016/j.polymer.2019.121791

Sabzi, M., Babaahmadi, M., Samadi, N., Mahdavinia, G. R., Keramati, M., and Nikfarjam, N. (2016). Graphene network enabled high speed electrical actuation of shape memory nanocomposite based on poly(vinyl acetate). Polym. Int. 66, 665-671. doi: 10.1002/pi.5303

Sanaz, S., Amin, B., Massoumeh, B., Mostafa, R., Farhang, A., and Ashkan, S. (2020). Effects of graphene quantum dot (GQD) on photoluminescence, mechanical, thermal and shape memory properties of thermoplastic polyurethane nanocomposites. Polym. Advan. Technol. doi: 10.1002/pat.4948

Sarabiyan, N., Babaie, A., Bagheri, M., Rezaei, M., Abbasi, F., and Shomali, A. (2020). Effects of graphene quantum dot (GQD) on photoluminescence, mechanical, thermal and shape memory properties of thermoplastic polyurethane nanocomposites. Polym. Advan. Technol. doi: 10.1016/j.compscitech.2020.108170

Sofla, R. L. M., Rezaei, M., Babaie, A., and Nasiri, M. (2019). Preparation of electroactive shape memory polyurethane/graphene nanocomposites and investigation of relationship between rheology, morphology and electrical properties. Compos. Part B-Eng. 175:107090. doi: 10.1016/j.compositesb.2019. 107090

Wang, E., Dong, Y., Islam, M. Z., Yu, L., Liu, F., Chen, S., et al. (2019a). Effect of graphene oxide-carbon nanotube hybrid filler on the mechanical property and thermal response speed of shape memory epoxy composites. Compos. Sci. Technol. 169, 209-216. doi: 10.1016/j.compscitech.2018.11.022

Wang, E., Wu, Y., Islam, M. Z., Dong, Y., Zhu, Y., Liu, F., et al. (2019b). A novel reduced graphene oxide/epoxy sandwich structure composite film with thermo-, electro- and light-responsive shape memory effect. Mater. Lett. 238, 54-57. doi: 10.1016/j.matlet.2018.11
Wang, J., Sun, L., Zou, M., Gao, W., Liu, C., Shang, L., et al. (2017). Bioinspired shape-memory graphene film with tunable wettability. Sci. Adv. 3, 1-7. doi: 10.1126/sciadv.1700004

Wang, W., Liu, D., Liu, Y., Leng, J., and Bhattacharyya, D. (2015). Electrical actuation properties of reduced graphene oxide paper/epoxy-based shape memory composites. Compos. Sci. Technol. 106, 20-24. doi: 10.1016/j. compscitech.2014.10.016

Wang, Y., Ma, T., Tian, W., Ye, J., Wang, X., and Jiang, X. (2018). Electroactive shape memory properties of graphene/epoxy-cyanate ester nanocomposites. Pigm. Resin. Technol. 47, 72-78. doi: 10.1108/PRT-04-2017-0037

Willian, H., and Cristina, T. (2020). The role of graphene on thermally induced shape memory properties of poly(lactic acid) extruded composites. J. Therm. Anal. Calorim. doi: 10.1007/s10973-020-09402-7

Yao, Y., Luo, Y., Xu, Y., Wang, B., Li, J., Deng, H., et al. (2018). Fabrication and characterization of auxetic shape memory composite foams. Compos. Part B-Eng. 152, 1-7. doi: 10.1016/j.compositesb.2018.06.027

Yi, D. H., Yoo, H. J., Mahapatra, S. S., Kim, Y. A., and Cho, J. W. (2014). The synergistic effect of the combined thin multi-walled carbon nanotubes and reduced graphene oxides on photothermally actuated shape memory polyurethane composites. J. Colloid Interf. Sci. 432, 128-134. doi: 10.1016/j.jcis. 2014.06.060

Yoonessi, M., Shi, Y., Scheiman, A. D., Lebron-Colon, M., Tigelaar, D. M., Weiss, R. A., et al. (2012). Graphene polyimide nanocomposites; thermal, mechanical, and high-temperature shape memory effects. ACS Nano 6, 7644-7655. doi: $10.1021 / \mathrm{nn} 302871 \mathrm{y}$

Yu, K., Liu, Y., and Leng, J. (2014). Shape memory polymer/CNT composites and their microwave induced shape memory behaviors. RSC Adv. 4, 2961-2968. doi: $10.1039 / \mathrm{c} 3 \mathrm{ra} 43258 \mathrm{k}$

Zhang, F., Zhou, T., Liu, Y., and Leng, J. (2015). Microwave synthesis and actuation of shape memory polycaprolactone foams with high speed. Sci. Rep. 5:11152. doi: $10.1038 /$ srep 11152

Zhang, L., Jiao, H., Jiu, H., Chang, J., Zhang, S., and Zhao, Y. (2016). Thermal, mechanical and electrical properties of polyurethane/ (3-aminopropyl) triethoxysilane functionalized graphene/epoxy resin interpenetrating shape memory polymer composites. Compos. Part A-Appl. S 90, 286-295. doi: 10. 1016/j.compositesa.2016.07.017

Zhang, Q., Wei, H., Liu, Y., Leng, J., and Du, S. (2016). Triple-shape memory effects of bismaleimide based thermosetting polymer networks prepared via heterogeneous crosslinking structures. RSC Adv. 6, 10233-10241. doi: 10.1039/ c5ra24247a

Zhang, Y., and Hu, J. (2020). Isocyanate modified go shape-memory polyurethane composite. Polymer 12:118. doi: 10.3390/polym12010118

Zhao, Q., Qi, H., and Xie, T. (2015). Recent progress in shape memory polymer: new behavior, enabling materials, and mechanistic understanding. Prog. Polym. Sci. 4, 79-120. doi: 10.1016/j.progpolymsci.2015.04.001

Zhao, W., Liu, L., Zhang, F., Leng, J., and Liu, Y. (2019). Shape memory polymers and their composites in biomedical applications. Mat. Sci. Eng. C-Mater. 97, 864-883. doi: 10.1016/j.msec.2018.12.054

Zhou, J., Li, H., Liu, W., Dugnani, R., Tian, R., Xue, W., et al. (2016). A facile method to fabricate polyurethane based graphene foams/epoxy/carbon nanotubes composite for electro-active shape memory application. Compos. Part A-Appl. S 91, 292-300. doi: 10.1016/j.compositesa.2016.10.021

Conflict of Interest: The authors declare that the research was conducted in the absence of any commercial or financial relationships that could be construed as a potential conflict of interest.

Copyright (c) 2020 Chen, Zhang, Liu and Liu. This is an open-access article distributed under the terms of the Creative Commons Attribution License (CC BY). The use, distribution or reproduction in other forums is permitted, provided the original author(s) and the copyright owner(s) are credited and that the original publication in this journal is cited, in accordance with accepted academic practice. No use, distribution or reproduction is permitted which does not comply with these terms. 